\title{
Influence of Hydrogenation on Residual Stresses in Oxygen- Implanted Ti-6Al-4V Alloy
}

\author{
S. Nsengiyumva ${ }^{1, a^{*}}$, T.P. Ntsoane ${ }^{2, b}$, M. Topic ${ }^{3, c}$, L. Pichon ${ }^{4, d}$ \\ ${ }^{1}$ Department of Physics and Electronics, Rhodes University, 6140 Grahamstown, South Africa \\ ${ }^{2}$ Research and Development Division, Necsa Limited, P.O. Box 582, Pretoria 0001, South Africa

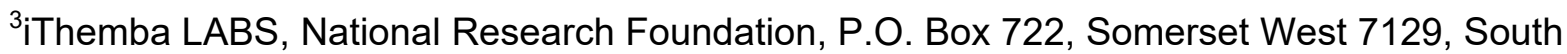 \\ Africa \\ ${ }^{4}$ Institute Pprime, UPR 3346CNRS, Université de Poitiers, ISAE-ENSMA, France \\ as.nsengiyumva@ru.ac.za, ${ }^{b}$ tshepo.ntsoane@necsa.co.za, ${ }^{c}{ }^{2}$ topic@tlabs.ac.za, \\ duc.pichon@univ-poitiers.fr
}

Keywords: Titanium Alloy, Oxygen Implantation, Hydrogenation, 2D XRD, Principal Stress

\begin{abstract}
We report the influence of hydrogenation on residual stresses in an oxygen-implanted Ti-6Al-4V alloy. Prior to hydrogenation, oxygen ions were implanted in Ti-6Al-4V samples at fluence $3 \times 10^{17}$ ions $/ \mathrm{cm}^{2}$ with energies of $50 \mathrm{keV}$ at room temperature and $550^{\circ} \mathrm{C}$ and $100 \mathrm{keV}$ and $150 \mathrm{keV}$ at $550^{\circ} \mathrm{C}$. Hydrogenation was carried out on all samples at $550^{\circ} \mathrm{C}$ for two hours. Residual stresses were analysed by X-ray diffraction using the $\sin ^{2} \psi$ method and components of in-plane principal stresses were determined. Our results show compressive stress relaxation in all samples implanted with 50,100 and $150 \mathrm{keV}$ at $550^{\circ} \mathrm{C}$ as compared to unimplanted sample. Subsequent to hydrogenation, a stress shift to tensile side is observed in all implanted samples at $550^{\circ} \mathrm{C}$.
\end{abstract}

\section{Introduction}

Owing to its high strength to weight ratio and good corrosion behaviour, Ti-6Al-4V is by far the most common Ti alloy used in a broad range of aerospace, marine, industrial, medical and commercial applications [1-3].

In recent years, Ti-6Al-4V has also attracted increasing research interest as a potential candidate for hydrogen storage due to its high affinity to absorb and release hydrogen $[4,5]$. Moreover recent studies [6,7] have suggested that a titanium oxide layer could enhance hydrogen absorption and promote Ti-6Al-4V alloy as an efficient hydrogen storage material. It has been established that the rate of hydrogen diffusion is higher by several orders of magnitude in the $\beta$ phase than in the $\alpha$ phase and that fully lamellar microstructure ( $\beta$ phase) would absorb more hydrogen than duplex microstructure [8]. Furthermore the higher solubility, as well as the rapid diffusion of hydrogen in the beta titanium results from the relatively open body centered cubic structure, which consists of 12 tetrahedral and octahedral interstices in comparison to 4 tetrahedral and 2 octahedral interstitial sites in the hexagonal closed packed lattice of alpha titanium [6]. The presence of hydrogen in both $\alpha$ and $\beta$ phases results in lattice expansion and the associated strain/stress fields could give rise to altered physical properties [9]. The aim of this study is to investigate the effect of hydrogenation on residual stresses of oxygen-implanted Ti$6 \mathrm{Al}-4 \mathrm{~V}$ alloy to obtain a better understanding on the relationship between the hydrogen absorption and the subsequent induced stress. It is worth mentioning that the amount of hydrogen absorbed in the samples under investigation has been reported in our recent publication [10]. 


\section{Experimental}

The material used in this study was Ti-6Al-4V alloy (grade-5) with typical composition of 6 wt.\% Al, 4 wt.\% V, 0.25 wt.\% $\mathrm{Fe}_{\max }, 0.2$ wt.\% $\mathrm{O}_{\max }$ and $\mathrm{Ti}$ as reminder (corresponding approximately to the atomic composition Ti0,86A10,10V0,04). The alloy was supplied in a form of annealed rod by GoodfellowC. The samples used were cut into disks (10 mm diameter and 2 $\mathrm{mm}$ thick), mounted in resin and polished using the following procedure. They were first grinded using 800 grit and 1200 grit SiC papers; after each grinding step, the samples were rinsed with water and cleaned ultrasonically in ethanol. Further polishing was performed using diamond paste with $9 \mu \mathrm{m}$ grain size. After cleaning, a mixture of OP-S (colloidal silica suspension) and $\mathrm{H}_{2} \mathrm{O}_{2}$ in 5:1 ratio was used for final polishing of the samples.

Oxygen $\mathrm{O}^{+}$ions at a fluence of $3.0 \times 10^{17}$ ions $/ \mathrm{cm}^{2}$ were implanted with 50,100 and $150 \mathrm{keV}$ energy and at a beam current of $10 \mu \mathrm{A}$ using in-line implanter Eaton NV 3206. The implantation was performed at room temperature and $550^{\circ} \mathrm{C}$.

All the samples were afterwards subjected to hydrogenation at $550^{\circ} \mathrm{C}$ for $2 \mathrm{hrs}$ in $15 \%$ hydrogen and $85 \%$ argon mixture at 1 atm pressure. The gas flow was kept constant at $14 \mathrm{~cm}^{3} / \mathrm{s}$. The samples were heated up to hydrogenation temperature and cooled down to room temperature at a rate of $5^{\circ} / \mathrm{min}$ under vacuum of $5.5 \times 10^{-2} \mathrm{mbar}$. Based on our previous experimental work, the optimum temperature for hydrogen absorption in the Ti-6Al-V alloy was determined as 550 ${ }^{\circ} \mathrm{C}[10,11]$.

X-ray stress investigation was done using a Bruker D8 Discover diffractometer equipped with a $1 / 4$ Eulerian cradle. The primary side optics included a graphite monochromator and a $0.8 \mathrm{~mm}$ collimator. No secondary optics on the detector side. Measurements were performed using a copper tube operating in spot focus mode, employing the $\psi$-tilt method. For a full stress tensor determination, measurements were done at six azimuth orientations, $\phi=0^{\circ}, 45^{\circ}$ and $90^{\circ}$, and $\phi$ $+180=180^{\circ}, 225^{\circ}$ and $270^{\circ}$ with each azimuth measured at eight tilt angles $\psi=0^{\circ}, 10^{\circ}, 20^{\circ}$, $30^{\circ}, 40^{\circ}, 50^{\circ}, 60^{\circ}$ and $70^{\circ}$. The rotation of $\phi$ by $180^{\circ}$ allowed measurement at negative tilt angles. Diffracted data was collected using a 2-D Våntec 500 detector. The diffraction peak corresponding to (211) at $\mathrm{d}=0.93217 \AA$ was used to measure residual strain. It was observed that some degree of texture was present in the samples and it was more pronounced in the hydrogenated samples (Fig. 1a) than in implanted samples (Fig. 1b). To minimise the texture effects on the analysis, samples were oscillated in the X-Y plane during measurements. The stress analysis of the data was done using the manufacturer proprietary software, Leptos v6.2. The maximum penetration depth of X-rays was found to be about $6 \mu \mathrm{m}$. 

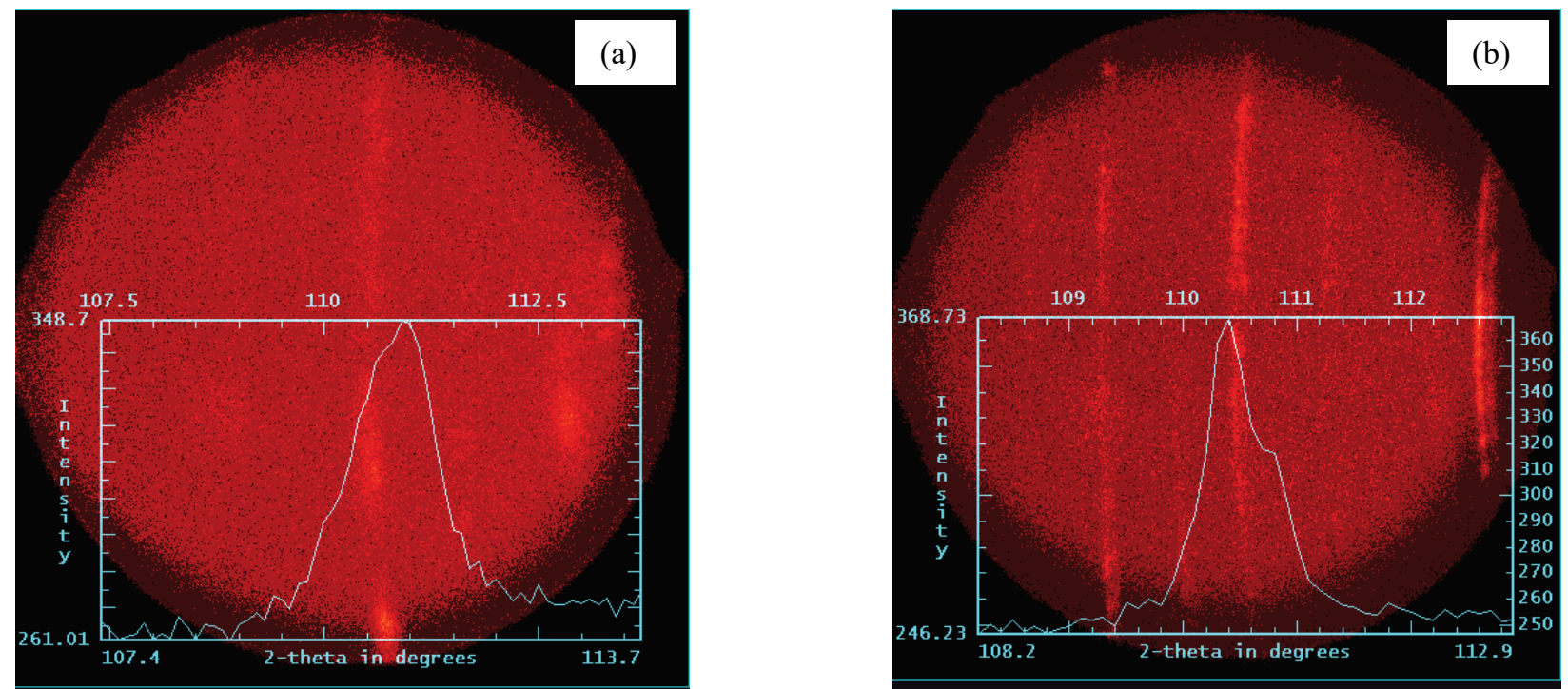

Fig. 1: 2D diffraction image of the reflection (211) used for strain measurement. (a) highly textured hydrogenated Ti-6Al-4V, (b) The texture is less pronounced in implanted Ti-6Al-4V alloy.

\section{Theory of 2D XRD stress determination}

Stress measurement with two-dimensional X-ray diffraction $\left(\mathrm{XRD}^{2}\right)$ is based on the fundamental relationship between the stress tensor and the diffraction cone distortion. The diffraction peak $2 \theta_{0}$ shifts are measured along the diffraction rings. Since a diffraction ring in a $2 \mathrm{D}$ pattern contains far more data points than a conventional diffraction peak, an $\mathrm{XRD}^{2}$ system can measure stress with higher accuracy and requires less data collection time, especially in dealing with highly textured materials, large grain size, small sample areas, weak diffraction, stress mapping, and stress tensor measurement [12].

The strain tensor $\varepsilon_{i j}$, determined in the sample coordinate system, and the distortion of the diffraction ring in a particular direction $(\eta, 2 \theta)$ are related by the two-dimensional fundamental equation for strain measurement

$$
f_{11} \varepsilon_{11}+f_{12} \varepsilon_{12}+f_{22} \varepsilon_{22}+f_{13} \varepsilon_{13}+f_{23} \varepsilon_{23}+f_{33} \varepsilon_{33}=\ln \left(\frac{\sin \theta_{0}}{\sin \theta}\right),
$$

where $f_{i j}$ are the strain coefficients, $\ln \left(\frac{\sin \theta_{0}}{\sin \theta}\right)$ is the diffraction cone distortion for a particular $(\eta, 2 \theta)$ position, $\theta_{0}$ and $\theta$ are the peak position for the stress-free material and stressed material, respectively.

In general, the stress tensor can be calculated from the measured strain tensor by Hooke's law. The stress tensor can be expressed in linear form as

$$
p_{11} \sigma_{11}+p_{12} \sigma_{12}+p_{22} \sigma_{22}+p_{13} \sigma_{13}+p_{23} \sigma_{23}+p_{33} \sigma_{33}=\ln \left(\frac{\sin \theta_{0}}{\sin \theta}\right) \text {, }
$$

where $p_{i j}$ are stress coefficients. 
For this investigation the true stress-free theta value $\theta_{0}$ was estimated from measurement of the side opposite to the implantation side. Any error in stress-free theta (stress-free lattice spacing) contributes only to pseudo-hydrostatic term [12] as $\sin ^{2} \psi$-method relies on the slope of plot and not the intercept.

\section{Results and discussion}

Figure 2 shows in-plane principal stresses $\sigma_{1}$ and $\sigma_{2}$ for unimplanted and implanted samples as a function of implantation energies of $50 \mathrm{keV}$ (at room temperature and $550^{\circ} \mathrm{C}$ ), $100 \mathrm{keV}$ and 150 $\mathrm{keV}$ at $550^{\circ} \mathrm{C}$. In Fig. $2 \mathrm{a}$ the principal stress component $\sigma_{l}$ of the unimplanted sample is compressive with a value of about $350 \mathrm{MPa}$. Upon implantation at $550^{\circ} \mathrm{C}$ with $50 \mathrm{keV}$, the stress value decreases to about $190 \mathrm{MPa}$. With further increased implantation energy, the stress value decreases to $298 \mathrm{MPa}$ and $228 \mathrm{MPa}$ for $100 \mathrm{keV}$ and $150 \mathrm{keV}$ respectively. The decrease in the stress value for samples at $550^{\circ} \mathrm{C}$ points to stress relaxation brought about by ion implantation. It can be observed however, that, at room temperature implantation with $50 \mathrm{keV}$ oxygen ions, the stress component $\sigma_{1}$ does not undergo stress relaxation; instead, the stress becomes more compressive, shifting from 340 to $410 \mathrm{MPa}$. In the case of the principal stress $\sigma_{2}$ (Fig. 2b), the stress relaxation is observed in samples implanted at room temperature as well as in samples implanted at $550^{\circ} \mathrm{C}$. The unimplanted sample has a stress value of $322 \mathrm{MPa}$. With implantation energy of $50 \mathrm{keV}$ at room temperature, the stress relaxes to $290 \mathrm{MPa}$ whereas it relaxes to 165 $\mathrm{MPa}, 120 \mathrm{MPa}$, and $98 \mathrm{MPa}$ for samples implanted at $550^{\circ} \mathrm{C}$ for $50 \mathrm{keV}, 100 \mathrm{keV}$ and $150 \mathrm{keV}$ respectively.
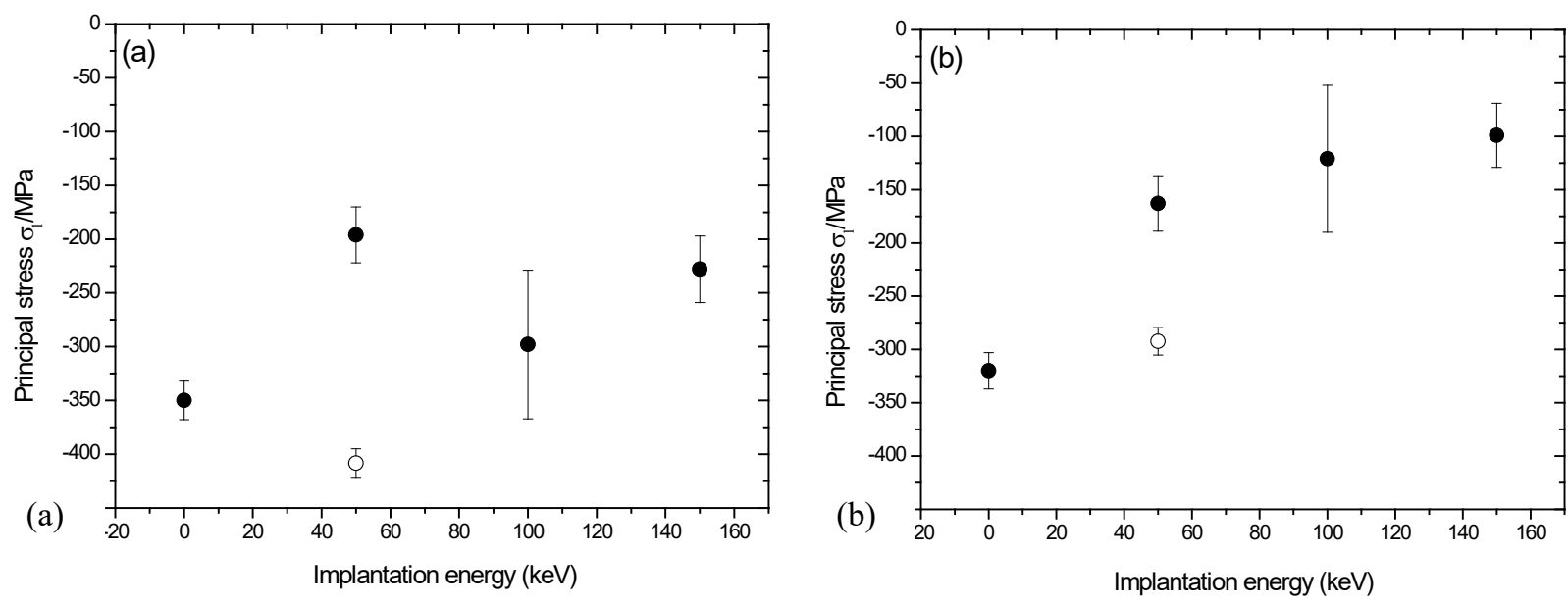

Fig. 2: Principal stress as a function of implantation energy for $\sigma_{1}$ component (a) and $\sigma_{2}$ component (b) for unimplanted sample, implanted samples with $50 \mathrm{keV}$ at RT (open circle) and $50 \mathrm{keV}, 100 \mathrm{keV}$ and $150 \mathrm{keV}$ at $550^{\circ} \mathrm{C}$ (filled circles).

Figure 3 shows in-plane principal stresses for hydrogenated unimplanted sample and hydrogenated implanted samples as a function of implantation energies: $50 \mathrm{keV}$ at room temperature and $50 \mathrm{keV}$ and $150 \mathrm{keV}$ at $550^{\circ} \mathrm{C}$. The hydrogenation of the sample implanted with $100 \mathrm{keV}$ is not shown in Fig. 3. The results obtained from this sample were deemed unreliable. Subsequent to hydrogenation at $550^{\circ} \mathrm{C}$ for two hours, it can be observed from Figs. $3 \mathrm{a}$ and $\mathrm{b}$ that the components $\sigma_{1}$ and $\sigma_{2}$ that were compressive upon implantation have become tensile. Only the stress component $\sigma_{2}$ of the unimplanted sample remains compressive following hydrogenation. 

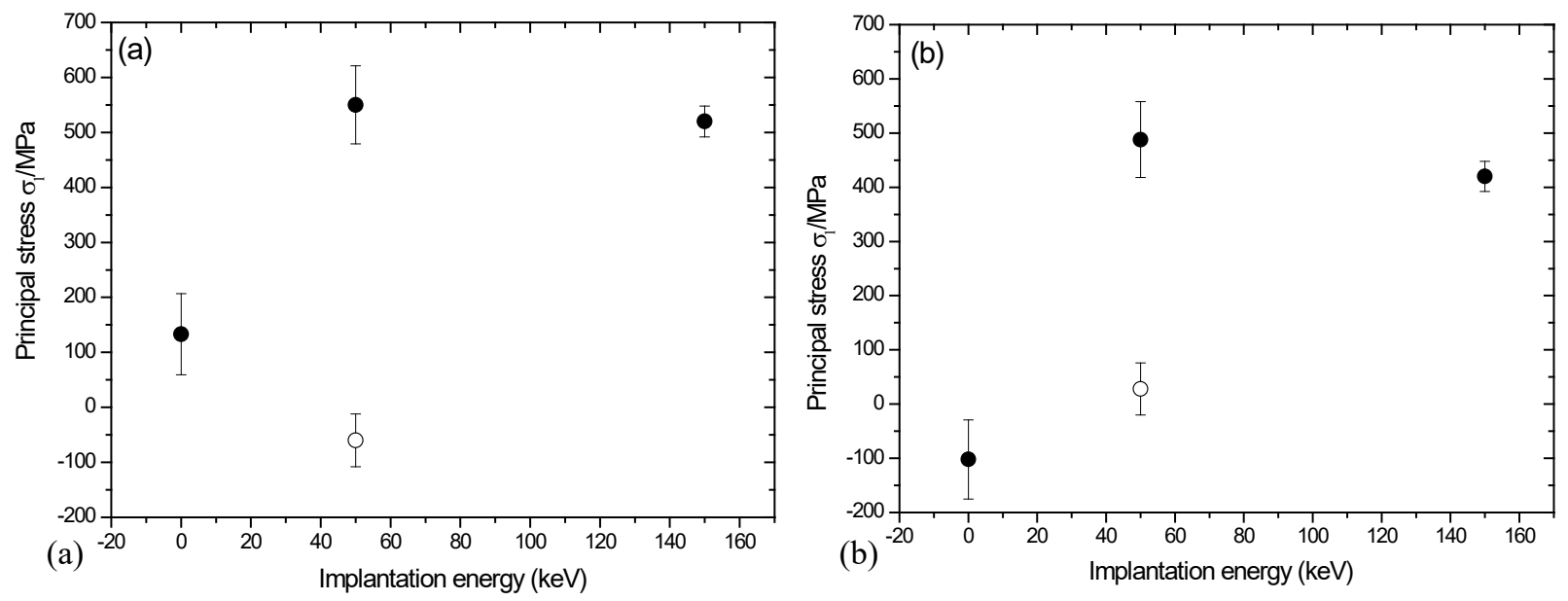

Fig. 3: Principal stress as a function of implantation energy after hydrogenation for component (a) and component (b) for unimplanted sample, implanted samples with $50 \mathrm{keV}$ and $150 \mathrm{keV}$.

The effect of hydrogenation on both stress components $\sigma_{1}$ and $\sigma_{2}$ with respect to unimplanted and implanted samples is shown in Fig. 4. In the case of $\sigma_{1}$ (Fig. $4 \mathrm{a}$ ), the stress value changes by about $500 \mathrm{MPa}$ for the unimplanted sample, $750 \mathrm{MPa}$ and $725 \mathrm{MPa}$ for implanted samples with $50 \mathrm{keV}$ and $150 \mathrm{keV}$ respectively. In the case of $\sigma_{2}$ (Fig. 4b), the stress value changes by 218 $\mathrm{MPa}$ for the unimplanted sample, $650 \mathrm{MPa}$ and $520 \mathrm{MPa}$ for implanted samples with $50 \mathrm{keV}$ and $150 \mathrm{keV}$ respectively.
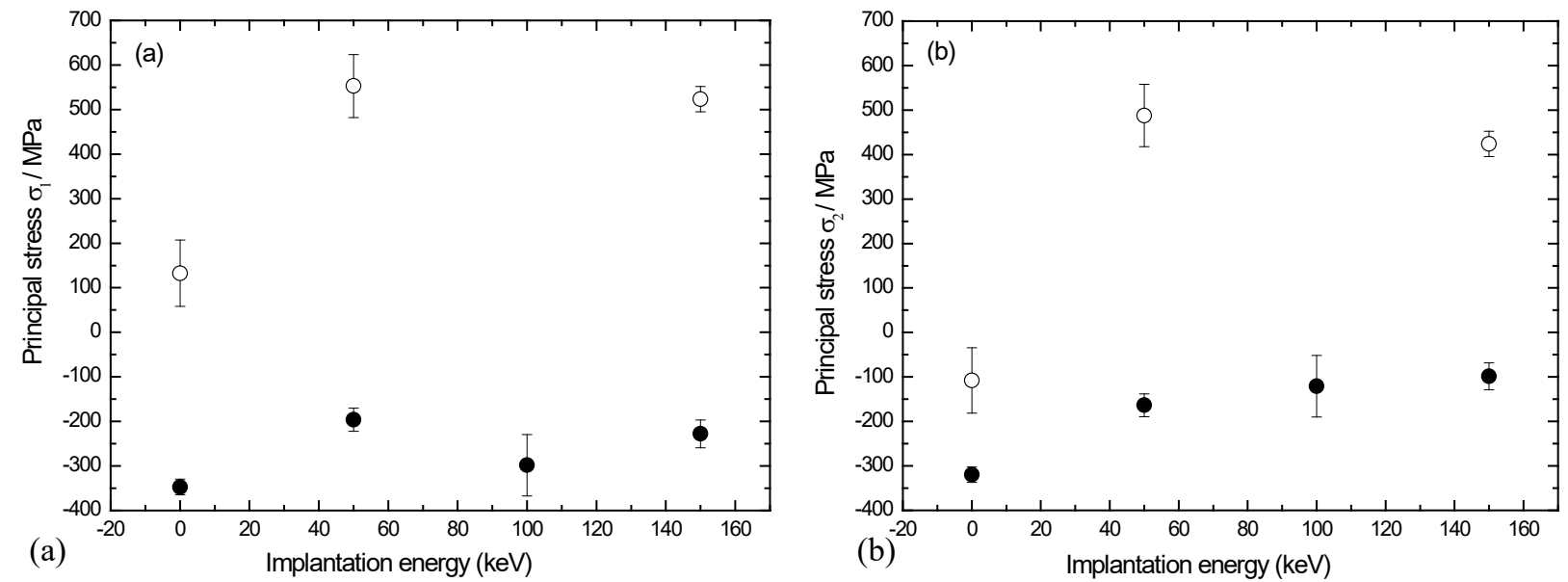

Fig. 4: Principal stress as a function of implantation energy showing the change of stress following hydrogenation. (a) $\sigma_{1}$ stress component. (b) $\sigma_{2}$ stress component. The full circles correspond to the stress values of unimplanted and implanted samples and the open circles correspond to the stress values of the same samples but after hydrogenation.

\section{Conclusion}

Residual stresses induced by ion implantation and hydrogenation in Ti-6Al-4V alloy have been investigated. Samples analysed were implanted with oxygen ions at $3 \times 10^{17}$ ions $/ \mathrm{cm}^{2}$ with energies of $50 \mathrm{keV}$ at room temperature and $550^{\circ} \mathrm{C}, 100 \mathrm{keV}$ and $150 \mathrm{keV}$ at $550^{\circ} \mathrm{C}$. Hydrogenation was carried out at $550^{\circ} \mathrm{C}$ for two hours. It was observed that oxygen implantation in Ti-6Al-4V alloy brings about stress relaxation of the pre-existing compressive stresses. Subsequent to hydrogenation, a stress shift from compressive to tensile was observed in all implanted samples at $550^{\circ} \mathrm{C}$. 


\section{Acknowledgements}

We are grateful to Rhodes University for financial support. We would also like to thank Marc Marteau at the Pprime Institute (France) for his assistance in ion implantation.

\section{References}

[1] M. Peters, J. Kumpfert, C.H. Ward and C. Leyens, TitaniumAlloys for Aerospace Applications, in: Titanium and Titanium Alloys, Adv. Eng. Mater. 5 (2003) 419-427. https://doi.org/10.1002/adem.200310095

[2] I. Gurrapa, Characterization of titanium alloy Ti-6al-4V for chemical, marine and industrial applications, Mater. Charact. 51 (2003) 131-139. https://doi.org/10.1016/j.matchar.2003.10.006

[3] C.N. Elias, J.H.V. Lima, R. Valiev and M.A. Meyers, Biomedical application of titanium and its alloys, JOM 60 (2008) 46-49. https://doi.org/10.1007/s11837-008-0031-1

[4] L. Bonaccorsi, L. Calabrese, A. Pintaudi, E. Proverbio, F. Aliotta, R. Ponterio , A. Scherillo and D. Tresoldi, Reversible hydrogen absorption in a Ti-6Al-4V alloy produced by mechanical alloying, Int. J. Hydrog. Energy 39(28) (2014) 15540-15548. https://doi.org/10.1016/j.ijhydene.2014.07.149

[5] A. López-Súarez, J. Rickards and R.Trejo-Luna, Mechanical and microstructural changes of Ti and Ti-6Al-4V alloy induced by the absorption and desorption of hydrogenJ. Alloys Compd. 457 (2008) 216-220. https://doi.org/10.1016/j.jallcom.2007.03.031

[6] A. López-Súarez, Influence of surface roughness on consecutively hydrogen absorption cycles in Ti-6Al-4V alloy, Int. J. Hydrog. Energy 35 (2010) 10404-10411. https://doi.org/10.1016/j.ijhydene.2010.07.163

[7] J.L. Blackburn, P.A. Parilla, T. Gennett, K.E. Hurst, A.C. Dillon and M.J. Heber, Measurement of the reversible hydrogen storage capacity of milligramTi-6Al-4V alloy samples with temperature programmed desorption and volumetric techniques, J. Alloys Compd. 454 (2008) 483-490.

[8] H.G. Nelson, D.P. William and J.E. Stein, Environmental hydrogen embrittlement of an $\alpha-\beta$ titanium alloy: Effect of microstructure, Metall. Mater. Trans. B 3 (1972) 473-479. https://doi.org/10.1007/BF02642051

[9] L. Miaoquan, Z. Weifu, Z. Tangkui, H. Hongliang and L. Zhigiang, Effect of microstructure of Ti-6Al-4V alloys, Rare Metal Mat. Eng. 39(1) (2010) 1-5. https://doi.org/10.1016/S18755372(10)60071-9

[10]M. Topic, L. Pichon, S. Nsengiyumva, G. Favaro, M. Dubuisson, S. Halindintwali, S.Mazwi, J. Sibanyoni, C. Mtshali and K. Corin, The effect of surface oxidation on hydrogen absorption in Ti-6Al-4V alloy studied by elastic recoil detection analysis (ERDA) and nanohardness techniques, J. Alloys Compd. $740 \quad$ (2018) 879-886. https://doi.org/10.1016/j.jallcom.2017.11.269

[11]S. Mazwi, Hydrogen storage in Ti-based coatings and Ti6Al4V alloy, Unpublished, Master's thesis, University of the Western Cape, Cape Town, South Africa.

[12]B. He Bob, Two-Dimensional X-Ray Diffraction, Wiley, 2009. 